\title{
Is Atrial Fibrillation an Independent Risk Factor for Stroke?*
}

\author{
Stephen J. Phillips
}

\begin{abstract}
That non-rheumatic atrial fibrillation is an independent risk factor for cerebral infarction has not been established with certainty. The rationale underlying contemporary clinical trials of warfarin therapy for the prevention of stroke in patients who have non-rheumatic atrial fibrillation is that the majority of strokes in such patients are due to cardiogenic cerebral embolism. However, there is evidence to suggest that the increased probability of stroke attributed to this arrhythmia is due to its association with other risk factors such as hypertension, diabetes mellitus, and atherosclerosis. The question of who should be anticoagulated is a major public health issue since atrial fibrillation is present in approximately ten per cent of the general population aged 65 or more years.
\end{abstract}

RÉSUMÉ: La fibrillation auriculaire est-elle un facteur de risque indépendant de l'accident cérébro-vasculaire? Il n'a jamais été établi avec certitude que la fibrillation auriculaire d'origine non-rhumatismale soit un facteur de risque indépendant de l'infarcissement cérébral. La justification des essais thérapeutiques avec la warfarine pour la prévention des accidents cérébro-vasculaires (ACV) chez les patients qui ont une fibrillation auriculaire non-rhumatismale est que la majorité des ACV chez ces patients est due à une embolie cérébrale cardiogénique. Cependant, certaines données suggèrent que la probabilité accrue d'ACV attribuée à ce type d'arythmie est due à son association à d'autres facteurs de risque, tels l'hypertension, le diabète et l'athérosclérose. La question à savoir qui devrait être anticoagulé est un sujet de débat important en santé publique, car la fibrillation auriculaire est présente chez approximativement dix pourcent de la population générale âgée de 65 ans et plus.

Can. J. Neurol. Sci. 1990; 17:163-168

Neurologists commonly find stroke patients to have atrial fibrillation yet cardiologists see many patients with atrial fibrillation who never have a stroke. What do unbiased observations tell us of the relationship between atrial fibrillation and stroke? Does atrial fibrillation itself cause embolic cerebral infarction, or have our observations been confounded by its association with other more important factors? Does anticoagulant therapy reduce the probability of cerebral infarction in patients who have atrial fibrillation? This essay discusses recent work in these areas.

\section{EPIdemiological Studies}

Population-based data are most likely to provide an unbiased view of the relationship between atrial fibrillation and stroke. In 1986, a survey of the population of Rochester, Minnesota, was conducted in order to determine the prevalence of cardiovascular disease.1,2 A stratified, random sample of 2,122 residents 35 years of age or older (Table 1) was selected using a random digit dialing technique. ${ }^{3}$ Persons living in nursing homes and senior citizen complexes who did not have private telephones were randomly selected from lists obtained from each facility. All subjects were visited in their place of residence by a field-worker who administered a questionnaire and took three blood pressure readings. The medical records of all subjects in the survey were reviewed. Information concerning cardiac and cerebral vascular conditions was obtained from entries made in the record before the date of the survey interview. 4 The medical records were retrieved using the Rochester Epidemiology Project medical records and record linkage system which provides access to the records of all patient-physician interactions involving residents of Rochester since the beginning of this century. ${ }^{5}$ Pre-determined criteria ${ }^{4}$ had to be met before a particular cardiac or cerebral vascular condition was judged to have been present. Electrocardiographic evidence was required for diagnosis of cardiac arrhythmias. Clinical criteria and ancillary investigations were used to define cardiac and cerebral vascular diseases. Mitral valvular atrial fibrillation was defined as atrial flutter/fibrillation found in association with mitral valve disease (excluding mitral value prolapse). Non-valvular atrial fibrillation was defined as atrial flutter/fibrillation found in the absence of mitral valve disease, mitral valve prolapse, and aortic valve disease. Lone atrial fibrillation was defined as atrial flutter/fibrillation occurring in the absence of hypertension (defined as a

From the Department of Medicine (Division of Neurology), Dalhousie University, and Camp Hill Medical Centre, Halifax, Nova Scotia

Received December 21, 1989. Accepted March 26, 1990

*Canadian Stroke Society Prize Essay, 1989

Reprint requests to: Dr. Stephen J. Phillips, Camp Hill Medical Centre, Department of Medicine, Gerard Hall, 5303 Morris Street, Halifax, Nova Scotia, Canada B3J 1B6 
Table 1: Age and Sex Stratification of a Random Sample of the Adult Population of Rochester, Minnesota, 1986

\begin{tabular}{crrrc}
\hline \hline \multirow{2}{*}{$\begin{array}{c}\text { Age Group } \\
\text { (years) }\end{array}$} & Men & Women & Total & $\begin{array}{c}\text { Sampling } \\
\text { Fraction* }\end{array}$ \\
\cline { 2 - 5 } & 222 & 216 & 438 & 0.057 \\
$35-44$ & 203 & 212 & 415 & 0.074 \\
$45-54$ & 209 & $206-$ & 415 & 0.090 \\
$55-64$ & 215 & 202 & 417 & 0.125 \\
$65-74$ & 174 & 263 & 437 & 0.137 \\
$\geq 75$ & 1,023 & 1,099 & 2,122 & 0.080 \\
\hline Total & & &
\end{tabular}

*Sample/population predicted from 1980 Census.

Reproduced with permission (see reference 1)

history of hypertension, or a mean blood pressure $\geq 160 / 95 \mathrm{~mm}$ $\mathrm{Hg}$ at the time of the survey interview) and in the absence of evidence of any congenital or acquired heart disease.

Atrial fibrillation was identified in $86(4.1 \%)$ subjects. Atrial flutter was identified in $18(0.9 \%)$ subjects, 4 of whom did not have atrial fibrillation. Thus, there were $90(4.2 \%)$ subjects who had atrial flutter/fibrillation (hereafter termed atrial fibrillation). Tables 2 and 3 show the age-sex-specific prevalence of the different categories of atrial fibrillation. The estimated prevalence of atrial fibrillation in the whole population of Rochester aged 35 or more years is shown in Table 4. Calculation of population prevalence required that the stratification of the sample be taken into account. This adjustment results in the population prevalence of atrial fibrillation being smaller than the sample prevalence.

The prevalence of atrial fibrillation, increased markedly with age, from zero among persons aged 35-44 years to $14.2 \%$ among those aged 75 or more years. Because we sampled the entire population of Rochester aged 35 or more years, and had access to all their medical records, our figures are considerably higher than any others reported in the literature. -11 $^{-11}$

The relationship between atrial fibrillation and cerebral infarction was studied in a cohort of 1,804 Rochester residents who were at least 50 years old and free of stroke in 1960, and who were followed up for 13 years. ${ }^{12} \mathrm{~A}$ time-dependent multivariate regression model was used to examine the following risk factors for cerebral infarction: age, sex, transient ischaemic attack, hypertension, hypertensive heart disease, use of antihypertensive medication, atrial fibrillation, coronary heart disease, congestive heart failure, left bundle branch block, valvular heart disease, diabetes mellitus, and arterial peripheral vascular disease.

During the 13 years of follow-up there were 110 first cerebral infarcts. Atrial fibrillation was present at baseline in 60 patients, and occurred in 109 patients during the period of follow-up. Seven cerebral infarcts occurred in the former group, and 6 occurred in the latter group of patients. For those patients who developed atrial fibrillation during follow-up, the median time from documentation of the arrhythmia to first cerebral infarction was 1.5 years. In univariate analysis, the relative risk of atrial fibrillation as a time-dependent risk factor was 2.9. However, in the time-dependent multivariate analysis, atrial fibrillation was not significant. The significant variables were age, male sex, hypertension, transient ischaemic attack, hypertensive heart disease, coronary heart disease, congestive heart failure, and diabetes. These data suggest that atrial fibrillation is an indicator of increased probability of cerebral infarction because of its association with other risk factors. Another cohort study ${ }^{13}$ done at the Mayo Clinic provides support for this contention.

All patients from Olmsted County, Minnesota, who were seen at the Mayo Clinic between 1950 and 1980 and had electrocardiographic evidence of atrial fibrillation, were identified using the Rochester Epidemiology Project medical records and records linkage system. Of these 3,623 patients, the 97 who were 60 years old or less and had lone atrial fibrillation (defined as atrial fibrillation in the absence of precipitating illness or overt cardiovascular disease, including hypertension) were fol-

Table 2: Age-Sex-Specific Prevalence of Intermittent and Persistent Atrial Flutter/Fibrillation in Rochester, Minnesota, 1986

\begin{tabular}{|c|c|c|c|c|c|c|}
\hline \multirow{3}{*}{$\begin{array}{l}\text { Age-Sex } \\
\text { Group }\end{array}$} & \multicolumn{4}{|c|}{ Atrial Flutter/Fibrillation } & \multirow{2}{*}{\multicolumn{2}{|c|}{ Total }} \\
\hline & \multicolumn{2}{|c|}{ Intermittent } & \multicolumn{2}{|c|}{ Persistent } & & \\
\hline & $\mathbf{n}$ & $(\%)$ & n & $(\%)$ & $\mathbf{n}$ & $(\%)$ \\
\hline \multicolumn{7}{|l|}{ Men } \\
\hline $35-44$ & 0 & & 0 & & 0 & \\
\hline $45-54$ & 0 & & 1 & $(0.5)$ & 1 & $(0.5)$ \\
\hline $55-64$ & 3 & (1.4) & 0 & & 3 & (1.4) \\
\hline $65-74$ & 9 & $(4.2)$ & 5 & (2.3) & 14 & (6.5) \\
\hline$\geq 75$ & 18 & $(10.3)$ & 10 & $(5.8)$ & 28 & (16.1) \\
\hline \multicolumn{7}{|l|}{ Women } \\
\hline $35-44$ & 0 & & 0 & & 0 & \\
\hline $45-54$ & 1 & $(0.5)$ & 0 & & 1 & $(0.5)$ \\
\hline $55-64$ & 3 & (1.5) & 0 & & 3 & (1.5) \\
\hline $65-74$ & 5 & $(2.5)$ & 1 & $(0.5)$ & 6 & $(3.0)$ \\
\hline$\geq 75$ & 18 & (6.8) & 16 & (6.1) & 34 & (12.9) \\
\hline
\end{tabular}

Table 3: Age-Sex-Specific Prevalence of Mitral Valvular, NonValvular, and Lone Atrial Flutter/Fibrillation in Rochester, Minnesota, 1986

\begin{tabular}{|c|c|c|c|c|c|c|}
\hline \multirow{3}{*}{$\begin{array}{l}\text { Age-Sex } \\
\text { Group }\end{array}$} & \multicolumn{6}{|c|}{ Atrial Flutter/Fibrillation } \\
\hline & \multicolumn{2}{|c|}{ Valvular } & \multicolumn{2}{|c|}{ Non-Valvular* } & \multicolumn{2}{|c|}{ Lone* } \\
\hline & $\mathbf{n}$ & $(\%)$ & $\mathbf{n}$ & $(\%)$ & $\mathbf{n}$ & $(\%)$ \\
\hline \multicolumn{7}{|l|}{ Men } \\
\hline $35-44$ & 0 & & 0 & & 0 & \\
\hline $45-54$ & 0 & & 1 & $(0.5)$ & 1 & $(0.5)$ \\
\hline $55-64$ & 0 & & 3 & (1.4) & 3 & (1.4) \\
\hline $65-74$ & 2 & $(0.9)$ & 12 & (5.6) & 4 & (1.9) \\
\hline$\geq 75$ & 2 & $(1.2)$ & 18 & $(10.3)$ & 2 & (1.2) \\
\hline \multicolumn{7}{|l|}{ Women } \\
\hline $35-44$ & 0 & & 0 & & 0 & \\
\hline $45-54$ & 1 & $(0.5)$ & 0 & & 0 & \\
\hline $55-64$ & 1 & $(0.5)$ & 2 & $(1.0)$ & 1 & $(0.5)$ \\
\hline $65-74$ & 0 & & 5 & (2.5) & 1 & $(0.5)$ \\
\hline$\geq 75$ & 9 & (3.4) & 21 & $(8.0)$ & 7 & (2.7) \\
\hline
\end{tabular}

*Non-valvular and lone atrial fibrillation are not mutually exclusive.

Table 4: Estimated Prevalence of Atrial Fibrillation/Flutter Among the Population of Rochester, Minnesota, Aged 35 or More Years

\begin{tabular}{lcc}
\hline \hline Category & $\begin{array}{c}\text { Estimated } \\
\text { Prevalence } \\
(\%)\end{array}$ & $\begin{array}{c}\text { 95\% Confidence } \\
\text { Limits }\end{array}$ \\
\hline Mitral valvular & 0.5 & $0.2,0.8$ \\
Non-valvular & 1.9 & $1.4,2.4$ \\
Lone & 0.7 & $0.4,1.0$ \\
All types & 2.8 & $2.2,3.3$ \\
\hline
\end{tabular}

Tables 2,3,4 - Reproduced with permission (see reference 4). 
lowed-up for a mean of 14.8 years. At 15 years, actuarial analysis showed that $1.3 \%$ of patients had had a stroke - a figure considerably lower than the expected rate of $3 \%$ (derived from the population of Rochester, Minnesota, with the same age and sex distribution). There was no significant difference in the probability of stroke between patients with chronic lone atrial fibrillation and those with recurrent episodes or a single episode.

It is of interest to compare these results with those from the Framingham Study. $14-17$ The Framingham investigators have reported a) that atrial fibrillation in the presence of rheumatic heart disease is associated with a 17 -fold increase in stroke incidence, ${ }^{14}$ while atrial fibrillation in the absence of rheumatic heart disease has a five-fold increase, 14,15 b) that $15 \%$ of all strokes are associated with atrial fibrillation, ${ }^{17}$ and c) that lone atrial fibrillation is associated with a four-fold increase in the risk of stroke. 16

The Framingham cohort included persons who were 30-62 years old and free of cardiovascular disease when examined in $1950,{ }^{18}$ and is therefore different from the Mayo Clinic cohorts. Follow-up has been longer in the Framingham Study, and examinations are done on a regular biennial schedule. Patients in the Mayo Clinic studies were seen as required by patients and physicians. In the 1960 Rochester cohort there was an average of 19 examinations per patient in 13 years or less of observation. The Framingham investigators' definition of stroke included transient ischaemic attack, cerebral infarction, intracerebral haemorrhage, and subarachnoid haemorrhage. ${ }^{14-18}$ The Mayo Clinic investigators 12 considered transient ischaemic attack a risk factor for stroke, excluded cases of subarachnoid haemorrhage, and used clinical criteria to distinguish cerebral infarction from intracerebral haemorrhage. Patients in whom atrial fibrillation was discovered at the time of stroke-onset were included in the estimation of relative risk by the Framingham investigators, 15,17 but excluded by the Mayo Clinic investigators. Lone atrial fibrillation was defined differently by the two groups of investigators. In the Mayo Clinic study, 12 patients who had hypertension were excluded, but pre-existing hypertension was present in $32 \%$ of the patients in the Framingham study. ${ }^{16}$

However, hypertension is a major risk factor for stroke; ${ }^{19}$ emboli from the fibrillating atrium probably rarely cause transient ischaemic attacks; 20 atrial fibrillation is frequently noted for the first time during hospitalization for stroke, 15 and may be the result rather than the cause of the stroke; data from hospital stroke registries ${ }^{21-23}$ show that atrial fibrillation is present in 2 to $6 \%$ of patients with intracerebral haemorrhage, and $2 \%$ of patients with subarachnoid haemorrhage. Therefore, the definitions used by the Framingham investigators will tend to result in inflated estimates of the relative risk of stroke in patients who have atrial fibrillation.

Other differences between the Framingham and Rochester studies concern the statistical methods, particularly the multivariate techniques, used to analyze the data. The two groups of investigators examined different risk factors using different techniques. The Framingham investigators have employed casecontrol techniques; their first report of the association between atrial fibrillation and stroke did not include multivariate analysis. ${ }^{14}$ In subsequent studies, ${ }^{15-17}$ the Framingham investigators employed logistic regression analysis to examine the relationship between atrial fibrillation and stroke in the presence of other risk factors. Analysis of time to stroke using Cox's propor- tional hazards model probably approximates the clinical situation more closely than a multiple logistic regression mode.

Interestingly, two British cohort studies of the relationship between atrial fibrillation and stroke also yielded disparate results. ${ }^{24}$ In the Whitehall Study of London Civil Servants, 19,018 men aged 40-69 were enrolled between 1967 and 1969 and followed up through 1984.24,25 At entry, 80 men were identified as having atrial fibrillation. "Adequate" follow-up data were available for 63 men who had non-rheumatic atrial fibrillation. Follow-up information for stroke (not defined) was obtained from death certificates (a notoriously unreliable source of stroke data ${ }^{26}$ ) and clinical records (not available for all subjects). The relative risk of fatal stroke for men with nonrheumatic atrial fibrillation was 6.9 (95\% confidence limits 3.0, 13.5).

In the British Regional Heart Study, 7,727 men aged 40-59 were enrolled in 24 towns in England, Wales, and Scotland in 1979-80.24.27 Of these men, 48 had non-rheumatic atrial fibrillation. Mortality follow-up, complete to June 1985, was obtained from death certificates. Stroke, clinically defined to include cerebral infarction, intracerebral haemorrhage, and subarachnoid haemorrhage, was monitored by inspection of a standard reporting card in each man's general practice record and by a questionnaire sent to each subject at 5 years. Only one stroke was identified among the men who had non-rheumatic atrial fibrillation, resulting in a relative risk of 2.3 which was not significantly different from unity. Three more years of follow-up are planned for this study.

\section{Clinical Aspects}

Clinical information concerning individual patients can be just as difficult to interpret as the data from large epidemiological studies. In a patient who has rheumatic heart disease, atrial fibrillation and a cerebral infarct, it is reasonable to assume that cardiogenic cerebral embolism was the mechanism of stroke. $28-30$ However, it is possible that endocardial changes are more important than atrial fibrillation in thrombogenesis in the rheumatic heart. ${ }^{31,32}$ Fortunately, rheumatic heart disease is uncommon. In the survey of Rochester, Minnesota, ${ }^{4}$ pure mitral stenosis was found in only 4 subjects, and the estimated prevalence of mitral valvular atrial fibrillation in the population aged 35 or more years was $0.5 \%$ (95\% confidence limits $0.2,0.8$ ). This estimate includes subjects with non-rheumatic valvular disease such as ischaemic mitral regurgitation. The low prevalence of rheumatic heart disease and mitral valvular atrial fibrillation may explain why these variables were not significant in the multivariate analysis used in the Rochester cohort study. 12

Thrombosis can occur in the fibrillating left atrium in the absence of rheumatic heart disease, but it is not known exactly why or how often it occurs. In an autopsy study 33 of 642 patients who had electrocardiographic evidence of atrial fibrillation, left atrial thrombus was found in $17.6 \%$ of patients with coronary artery disease and/or hypertensive cardiovascular disease, $33 \%$ of patients with valvular disease or congenital heart lesions, and $2.3 \%$ of age-matched controls without atrial fibrillation.

Postmortem diagnosis of cardiogenic cerebral embolism is not always possible, ${ }^{33}$ particularly in the presence of atheroscle- 
rotic lesions, or if the stroke was remote. Therefore, it is not surprising that autopsy studies have provided conflicting data concerning the frequency of systemic embolism from the fibrillating atrium. In one study of a thousand autopsies, ${ }^{34}$ only 1 case of embolization was found among 52 patients who had atrial fibrillation and arteriosclerotic heart disease. In another autopsy study ${ }^{35}$ of 333 patients who had atrial fibrillation, symptomatic cerebral and non-cerebral emboli (confirmed surgically or pathologically) occurred in $41 \%$ (29/70) of patients with mitral valve disease, $35 \%(59 / 171)$ of patients with ischaemic heart disease, and in $7 \%(4 / 58)$ of a control group of patients who had ischaemic heart disease without atrial fibrillation.

Intra-atrial thrombus cannot always be detected during life. Two-dimensional echocardiography correctly identifies left atrial thrombus about $60 \%$ of the time, ${ }^{36}$ and is not capable of detecting thrombus in the left atrial appendage. 36,37 Computerized tomography appears to be more sensitive, and is capable of delineating thrombus in the left atrial appendage. ${ }^{38}$ Angiocardiography is not without risk to the patient and is seldom performed solely to identify intra-atrial thrombus. In the future, transoesophageal echocardiography, ${ }^{39}$ ultrafast cardiac computerized tomography, ${ }^{40}$ and magnetic resonance imaging are likely to find increasing application in this area.

There has been a tendency to attribute any stroke in a patient who has atrial fibrillation to embolism from the left atrium. ${ }^{14-17}$ However, stroke patients with non-rheumatic atrial fibrillation frequently have evidence of an alternative potential mechanism of cerebral infarction. ${ }^{41,42}$ Precise diagnosis of the mechanism in a given patient is exceedingly difficult.43-45 Although traditionally considered to be abrupt in onset, ${ }^{43}$ embolic strokes of nonsudden onset have been described; 46 conversely, progression of stroke symptoms after arrival at hospital has been found to be as common among patients with atrial fibrillation as among others. ${ }^{47}$ Haemorrhagic infarction, considered to be virtually pathognomonic of cardioembolic stroke, ${ }^{48}$ can occur in cases of atherothromboembolic stroke. ${ }^{45}$ Patients with atrial fibrillation and congestive heart failure appear to be at increased risk of stroke, ${ }^{49}$ but this may be due to haemodynamic factors ${ }^{50}$ rather than cardiogenic cerebral embolism. Whether an enlarged left atrium predisposes to thromboembolism in patients with atrial fibrillation is controversial. $51-53$ Thus, there is an understandable reluctance on the part of many physicians to subject stroke patients, particularly the elderly, to extensive investigation which may neither resolve the issue of mechanism nor influence management of the patient.

\section{THERAPY}

It is impossible to deny that cardiogenic embolism is a mechanism of cerebral infarction in some patients who have atrial fibrillation. However, we may have over-estimated the importance of atrial fibrillation itself in the pathogenesis of stroke. The problems of determining the mechanism of cerebral infarction are inextricably intertwined with the issue of therapy. If atrial fibrillation predisposes to intra-atrial thrombosis and systemic embolism, can anticoagulant therapy lower the probability of this occurring? It is generally accepted that the answer to this question is yes if the patient has rheumatic heart disease. 54,55 However, the evidence on which this view is based comes from suboptimal studies 56 and, because rheumatic heart disease is uncommon in Western society, it is unlikely that this belief will ever be challenged by a randomized clinical trial.

What about the more common clinical problem - the elderly patient with non-valvular atrial fibrillation? If atrial fibrillation is merely a marker of diffuse vascular disease, is it reasonable to administer anticoagulant therapy with the expectation that it will reduce the likelihood of cerebral infarction due to atherothromboembolism and hypertensive arteriolar disease? Anticoagulant therapy would appear to be rational but hypertensive arteriolar disease predisposes to intracerebral haemorrhage as well as cerebral infarction, 19 arterial thrombi are composed mainly of platelets, 57 and warfarin exerts its antithrombotic effect by inhibiting fibrin formation, not platelet function. ${ }^{58}$ What are the mechanisms of thrombogenesis in the nonrheumatic fibrillating left atrium? Bleeding complications are less frequently associated with aspirin therapy than with warfarin therapy. Aspirin is known to reduce the frequency of recurrent focal cerebral ischaemic events by about one third, 59 but it is not known whether aspirin protects against first stroke in patients with non-valvular atrial fibrillation. In such patients, which drug is more efficacious, aspirin or warfarin? These important unresolved issues have prompted clinical trials in Europe, the United States, and Canada.

The results of the Copenhagen AFASAK Study60 suggest that warfarin is beneficial in patients with chronic non-rheumatic atrial fibrillation. In this randomized trial, 335 patients received warfarin (median age 73 years, range 41-88), 336 patients received aspirin $75 \mathrm{mg}$ once daily (median age 75 years, range 40-91), and 336 patients received placebo (median age 75 years, range 38-91). Warfarin was administered openly; aspirin and placebo were given double-blind. Therapeutic anticoagulation was defined as an International Normalized Ratio (INR) in the range 4.2-2.8. The follow-up time was 2 years for each patient. The incidence of stroke, TIA, non-cerebral embolism, and vascular death were significantly lower in the warfarin group (5 events) than in the aspirin (20 events) and placebo (21 events) groups. The rate of thromboembolic stroke and TIA for the aspirin and placebo groups combined was 2.7 per 100 patientyears; the rate of thromboembolic stroke was 2.3 per 100 patient-years. In the Framingham Study, the stroke rate (all types, including TIA) among individuals with idiopathic atrial fibrillation was 4.2 per 100 person-years. ${ }^{14}$ The AFASAK protocol did not require investigation of the mechanism of cerebral ischaemic events. One patient taking warfarin had a fatal intracerebral haemorrhage (INR $=3.7$ ). No intracerebral haemorrhages were detected among the patients taking aspirin or placebo (76\% of patients with cerebrovascular events had a CT scan or necropsy). Non-fatal bleeding complications resulted in withdrawal of 21 patients from the warfarin group. The frequency of warfarin-associated bleeding in this study (3.3 bleeds per 100 person-years) compares favourably with previously published rates of 2 to 22 per 100 person-years. ${ }^{61}$ These observations support current expert opinion 62 that less intense anticoagulation is as effective as more intense, and is associated with fewer complications.

Since clinical practice in such a controversial area of medicine is unlikely to be substantially altered by the results of a single study, the other trials have not been discontinued. A metaanalysis has been proposed 63 to analyze the risk of stroke and 
the influence of anticoagulant therapy among subgroups of patients with atrial fibrillation, for example those with left atrial enlargement.

In the American Stroke Prevention in Atrial Fibrillation Study, ${ }^{64}$ patients with non-valvular atrial fibrillation are randomly assigned to warfarin, aspirin $325 \mathrm{mg}$ daily, or placebo. Aspirin and placebo are administered in a double-blind manner, while warfarin recipients are not blinded. Prothrombin times are maintained at 1.3-1.8 times control values. After 728 patientyears of follow-up the stroke rate was 4.9 per cent. 65 At 7 of the 15 participating centres, 174 unselected patients had carotid ultrasound examinations performed at baseline. ${ }^{66}$ Carotid stenosis of $50 \%$ or more was found in $17 \%$ of these patients, and was bilateral in $8 \%$. This frequency is approximately twice that in an age-matched general population. These data highlight the problem of multiple stroke mechanisms existing in the same patient, and support the contention that non-valvular atrial fibrillation is a marker of advanced vascular disease.

The Canadian Atrial Fibrillation Anticoagulation Study is a double-blind, placebo-controlled randomized clinical trial of warfarin therapy in patients who have non-valvular atrial fibrillation. All patients are managed as if they are receiving warfarin. The dose of warfarin is adjusted by an anticoagulation supervisor in each centre to maintain the INR in the range 2.0 to 3.0. Tables of sham INR values are used to adjust the dose of placebo so that patients and physicians remain "blind". The primary outcome events are the first occurrence of retinal or cerebral infarction, or an embolic event involving the kidney, limbs, or mesentery. The safety of anticoagulation will be determined by the occurrence of intracranial haemorrhage or any fatal haemorrhage. Patients suspected of having a stroke undergo clinical evaluation by a study neurologist, computerized tomography of the brain, and either ultrasonography or intravenous digital subtraction angiography to assess the extracranial cerebral arteries. Recruitment, currently taking place in 11 centres across the county, is expected to be completed in 1991 .

\section{CONCLUding REMARKS}

It is unlikely that the clinical trials currently in progress will be able to distinguish, with certainty, whether any reduction in the frequency of cerebral infarction is due to prevention of cardiogenic cerebral embolism, or modification of other mechanisms of ischaemic stroke, or both. However, these studies represent the most rigorous examination ever of the use of anticoagulant therapy for cerebrovascular disease. Demonstration of a reduction in the frequency of stroke by either warfarin or aspirin will have major implications for the health care system because stroke prevention is an important public health issue and atrial fibrillation is a common arrhythmia.

\section{ACKNOWLEDGEMENTS}

Dr. Phillips receives support from the W. Garfield Weston Foundation of Toronto, and the Nova Scotia Heart Foundation. Details of the CAFA Study protocol are given with permission from Dr. Stuart Connolly.

\section{REFERENCES}

1. Phillips SJ. Whisnant JP, O'Fallon WM, et al. A community blood pressure survey: Rochester, Minnesota, 1986. Mayo Clin Proc 1988; 63: 691-699.
2. Phillips SJ, Whisnant JP, O'Fallon WM. Correction. Mayo Clin Proc 1989; 64: 267.

3. Dillman DA. Mail and telephone surveys: the total design method. New York, John Wiley \& Sons, 1978.

4. Phillips SJ, Whisnant JP, O'Fallon WM, et al. Prevalence of cardiovascular disease and diabetes mellitus in Rochester, Minnesota. Mayo Clin Proc 1990 (in press).

5. Kurland LT, Molgaard CA. The patient record in epidemiology. Sci Am 245: 54-63, October 1981.

6. Hiss RG, Lamb LE. Electrocardiographic findings in 122,043 individuals. Circulation 1962; 25: 947-961.

7. Ostrander LD, Brandt RL, Kjelsbert MO, et al. Electrocardiographic findings among the adult population of a total natural community. Circulation $1965 ; 31: 888-898$.

8. Orndahl G, Thulesius O, Hood B. Incidence of persistent atrial fibrillation and conduction defects in coronary artery disease. Am Heart J 1972; 84: 120-131.

9. Kitchin AH, Milne JS. Longitudinal survey of ischaemic heart disease in a randomly selected sample of an older population. $\mathrm{Br}$ Heart J 1977; 39: 889-893.

10. Rose G, Baxter PJ, Reid DD, et al. Prevalence and prognosis of electrocardiographic findings in middle-aged men. $\mathrm{Br}$ Heart $\mathrm{J}$ 1978; 40: 636-643.

11. Onundarson PT, Thorgeirsson G, Jonmundsson E, et al. Chronic atrial fibrillation - epidemiologic features and 14 year followup: a case control study. Eur Heart J 1987; 8: 521-527.

12. Davis PH, Dambrosia JM, Schoenberg BS, et al. Risk factors for ischemic stroke: a prospective study in Rochester, Minnesota. Ann Neurol 1987; 22: 319-327.

13. Kopecky SL, Gersh BJ, McGoon MD, et al. The natural history of lone atrial fibrillation: a population-based study over three decades. N Engl J Med 1987; 317: 669-674.

14. Wolf PA, Dawber TR, Thomas HE Jr, et al. Epidemiologic assessment of chronic atrial fibrillation and risk of stroke: the Framingham study. Neurology 1978; 28: 973-977.

15. Wolf PA, Kannel WB, McGee DL, et al. Duration of atrial fibrillation and imminence of stroke: the Framingham study. Stroke 1983; 14: 664-667.

16. Brand FN, Abbott RD, Kannel WB, et al. Characteristics and prognosis of lone atrial fibrillation: 30-year follow-up in the Framingham study. JAMA 1985; 254: 3449-3453.

17. Wolf PA, Abbott RD, Kannel WB. Atrial fibrillation: a major contributor to stroke in the elderly. Arch Int Med 1987; 147: 15611564.

18. Dawber TR. The Framingham study: the epidemiology of atherosclerotic disease. Harvard University Press, 1980.

19. Phillips SJ, Whisnant JP. Hypertension and stroke. In: Laragh JH, Brenner RM, eds. Hypertension; Pathophysiology, Diagnosis, and Management. New York: Raven Press 1990; 417-431.

20. Harrison MJG, Marshall J. Atrial fibrillation, TIAs and completed strokes. Stroke 1984; 15: 441-442.

21. Mohr JP, Caplan LR, Melski JW, et al. The Harvard Cooperative Stroke Registry: a prospective registry. Neurology 1978; 28: 754-762.

22. Foulkes MA, Wolf PA, Price TR, et al. The Stroke Data Bank: design, methods, and baseline characteristics. Stroke 1988; 19: 547-554.

23. Bogousslavsky J, Van Melle G, Regli F. The Lausanne Stroke Registry: analysis of 1,000 consecutive patients with first stroke. Stroke 1988; 19: 1083-1092.

24. Flegel KM, Shipley MJ, Rose G. Risk of stroke in non-rheumatic atrial fibrillation. Lancet 1987; i: 526-529.

25. Reid DD, Brett GZ, Hamilton PJS, et al. Cardiorespiratory disease and diabetes among middle-aged male civil servants. Lancet 1974; i: 469-473.

26. Corwin LI, Wolf PA, Kannel WB, et al. Accuracy of death certification of stroke: the Framingham study. Stroke 1982; 13:818821.

27. Shaper AG, Pocock SJ, Walker M, et al. British Regional Heart Study: cardiovascular risk factors in middle-aged men in 24 towns. Br Med J 1981; 283: 179-186.

28. Daley R, Mattingly TW, Holt CL, et al. Systemic arterial embolism in rheumatic heart disease. Am Heart J 1951; 42: 566-581. 
29. Graham GK, Taylor JA, Ellis LB, et at. Studies in mitral stenosis. II. A correlation of post-mortem findings with the clinical course of the disease in one hundred and one cases. Arch Intern Med 1951; 88: 532-547.

30. Coulshed N, Epstein EJ, MacKendrick CS, et al. Systemic embolism in mitral valve disease. Br Heart J 1970; 32: 26-34.

31. Wallach JB, Lukash L, Angrist AA. An interpretation of the incidence of mural thrombi in the left auricle and appendage with particular reference to mitral commissurotomy. Am Heart $\mathbf{J}$ 1953; 45: 252-254.

32. Wallach JB, Lukash L, Angrist AA. The mechanism of formation of left auricular mural thrombi. Am J Med 1954; 16: 543-548.

33. Aberg H. Atrial fibrillation. I. A study of atrial thrombosis and systemic embolism in a necropsy material. Acta Med Scand 1969; 185: 373-379.

34. Beer DT, Ghitman B. Embolization from the atria in arteriosclerotic heart disease. JAMA 1961; 177: 287-291.

35. Hinton RC, Kistler JP, Fallon JT, et al. Influence of etiology of atrial fibrillation on incidence of systemic embolism. Am J Cardiol 1977; 40: 509-513.

36. Shrestha NK, Moreno FL, Narciso FV, et al. Two-dimensional echocardiographic diagnosis of left atrial thrombus in rheumatic heart disease: a clinicopathologic study. Circulation 1983; 67: 341-347.

37. Schweizer P, Bardos P, Erbel R, et al. Detection of left atrial thrombi by echocardiography. $\mathrm{Br}$ Heart J 1981; 45: 148-156.

38. Tomoda $\mathrm{H}$, Hoshiai $\mathrm{M}$, Furuya $\mathrm{H}$, et al. Evaluation of intracardiac thrombus with computed tomography. Am J Cardiol 1983; 51: 843-852.

39. Seward JB, Khandheria BK, Oh JK, et al. Transesophageal echocardiography: technique, anatomic correlations, implementation, and clinical applications. Mayo Clin Proc 1988; 63: 649680 .

40. Helgason CM, Chomka E, Louie, et al. The potential role for ultrafast cardiac computed tomography in patients with stroke. Stroke 1989; 20: 465-472.

41. Starkey I, Warlow C. The secondary prevention of stroke in patients with atrial fibrillation. Arch Neurol 1986; 43: 66-68.

42. Sherman DG, Hart RG, Easton JD. The secondary prevention of stroke in patients with atrial fibrillation. Arch Neurol 1986; 43: 68-70.

43. Cerebral Embolism Task Force. Cardiogenic brain embolism. Arch Neurol 1986; 43: 71-84.

44. Ramirez-Lassepas M, Cipolle RJ, Bjork RJ, et al. Can embolic stroke be diagnosed on the basis of neurologic clinical criteria? Arch Neurol 1987; 44: 87-89.

45. Britton $M$, Gustafsson C. Non-rheumatic atrial fibrillation as a risk factor for stroke. Stroke 1985; 16: 182-188.

46. Fisher CM, Pearlman A. The nonsudden onset of cerebral embolism. Neurology 1967; 17: 1025-1032.

47. Roden A, Britton M. Progression of stroke after arrival at hospital. Acta Nuerol Scand 1982; 66 (Suppl 91): 43.

48. Fisher CM, Adams RD. Observations on brain embolism with special reference to hemorrhagic infarction. In: Furlan AJ, ed. The Heart and Stroke: Exploring Mutual Cerebrovascular and Cardiovascular Issues. Berlin Heidelberg: Springer-Verlag 1987: 17-36.

49. Kannel WB, Abbott RD, Savage DD, et al. Epidemiologic features of chronic atrial fibrillation: the Framingham Study. $\mathrm{N}$ Eng $\mathrm{J}$ Med 1982; 306: 1018-1022.

50. Lavy S, Stern S, Melamed E, et al. Effect of chronic atrial fibrillation on regional cerebral blood flow. Stroke 1980; 11: 35-38.
51. Caplan LR, D'Cruz I, Hier DB, et al. Atrial size, atrial fibrillation, and stroke. Ann Neurol 1986; 19: 158-161.

52. Aronow WS, Gutstein H, Hsieh FY. Risk factors for thromboembolic stroke in elderly patients with chronic atrial fibrillation. Am J Cardiol 1989; 63: 366-367.

53. Flegel KM, Hanley J. Risk factors for stroke and other embolic events in patients with nonrheumatic atrial fibrillation. Stroke 1989; 20: 1000-1004.

54. Levine HJ, Pauker SG, Salzman EW. Antithrombotic therapy in valvular heart disease. Chest 1986; 89: 36S-45S.

55. Cerebral Embolism Task Force. Cardiogenic brain embolism: the second report of the Cerebral Embolism Task Force. Arch Neurol 1989; 46: 727-743.

56. Genton E. Barnett HJM, Fields WS, et al. Cerebral ischemia: the role of thrombosis and of antithrombotic therapy. Stroke 1977; 8: 150-175.

57. Roberts HR, Braunstein K. The thrombotic state. In: Lundblad RL, Roberts HR, eds. Chemistry and Biology of Heparin. New York/Amsterdam: Elsevier Science Publishing Co Inc, 1981: 487-496.

58. Wessler S, Gitel SN. Pharmacology of heparin and warfarin. J Coll Cardiol 1986; 8: 10B-20B

59. Antiplatelet Trialists' Collaboration. Secondary prevention of vascular disease by prolonged antiplatelet treatment. $\mathrm{Br}$ Med J 1988; 296: 320-331.

60. Petersen P, Boysen G, Godtfredsen J, et al. Placebo-controlled randomized trial of warfarin and aspirin for prevention of thromboembolic complications in chronic atrial fibrillation. Lancet 1989; i: $175-179$.

61. Levine MN, Raskob G, Hirsh J. Haemorrhagic complications of long-term anticoagulant therapy. Chest 1986; 89 (Suppl): 16S$25 S$.

62. Hirsh J. Levine MN. Therapeutic range for the control of oral anticoagulant therapy. Arch Neurol 1986; 43: 1162-1164.

63. Walker MD. Atrial fibrillation and antithrombotic prophylaxias: a prospective meta-analysis. Lancet 1989; i: 325-326.

64. Feinberg WM, Biller J, Helgason CM, et al. Stroke prevention in atrial fibrillation study: progress report of an ongoing cooperative study. (Abstract). Neurology 1989; 39 (Suppl 1): 159.

65. Miller VT, Cohen BA, Feinberg WH, et al. Strokes in patients with nonvalvular atrial fibrillation (Abstract). Circulation 1989;80 (Suppl II): II-404.

66. Tegeler $\mathrm{CH}$. Stroke prevention in atrial fibrillation study: carotid stenosis study group. Carotid stenosis in atrial fibrillation. (Abstract). Neurology 1989; 39 (Suppl 1): 159.

\section{Note added in proof:}

The Stroke Prevention in Atrial Fibrillation Study Group Investigators recently announced ${ }^{67}$ that the placebo arm of their trial has been closed because an interim analysis showed a statistically significant benefit from active antithrombotic therapy. The trial is continuing to compare aspirin and warfarin. Because of these results, the Canadian Atrial Fibrillation Anticoagulation Study has been terminated.

67. Stroke Prevention in Atrial Fibrillation Study Group Investigators. Preliminary report of the Stroke Prevention in Atrial Fibrillation Study. N Engl J Med 1990; 322: 863-868. 


\section{Neurosurgical Symposium}

\section{The following papers were presented at the annual William S. Keith Visiting Professorship in Neurosurgery}

\section{Acknowledgements}

Publication of this symposium was supported by financial assistance from the following contributors:

Sigmacon

Carl Zeiss

Zimmer of Canada

Cyanamid Canada

Bremer Orthopedics

Cadwell Labs

Medtronic

Ethicon Ltd.

Pfizer
Valleylab

Codman

Novopharm

Davis \& Geck

Sandoz

Upjohn

Syntex

Ciba-Geigy

Mr. \& Mrs. K. Yaeger 